\title{
LOGÍSTICA REVERSA DO ÓLEO ISOLANTE DE TRANSFORMADORES EM UMA EMPRESA DO SETOR ELÉTRICO
}

\section{REVERSE LOGISTICS OF INSULATION OIL FROM TRANSFORMERS IN A COMPANY FROM ELECTRICITY SECTOR}

\author{
Maruschka Carneiro Rodrigues ${ }^{1}$; Nathália Almeida Castro Rodrigues ${ }^{2}$; André Cristiano Silva \\ Melo $^{3}$; Denilson Ricardo de Lucena Nunes ${ }^{4}$ \\ ${ }^{1}$ Universidade do Estado do Pará - UEPA - Belém, Pa; Brasil, Engenheira de produção. \\ maruschka.cr@gmail.com \\ ${ }^{2}$ Universidade do Estado do Pará - UEPA - Belém, Pa; Brasil, formanda em Engenharia de \\ produção. \\ nathaliarods@hotmail.com \\ ${ }^{3}$ Universidade do Estado do Pará - UEPA - Belém, Pa; Brasil, Prof. D.Sc. \\ acsmelo@yahoo.com.br \\ ${ }^{4}$ Universidade do Estado do Pará - UEPA - Belém, Pa; Brasil, Prof. D.Sc. \\ denilson.lucena@ibest.com.br
}

\begin{abstract}
Resumo
Este artigo teve por objetivo identificar os canais reversos de resíduos pós-consumo, sob a ótica de seus componentes logísticos, em uma empresa do setor elétrico no estado do Pará. Para tanto, foi realizado um levantamento bibliográfico sobre logística reversa e componentes logísticos, que permitiu, juntamente com o levantamento em campo, descrever a cadeia reversa do resíduo de óleo mineral isolante produzido pela empresa objeto deste estudo. Dessa forma, foram identificados sobre esse resíduo seus volumes processados, os processos envolvidos no transporte e manuseio, $e$ os principais pontos de descarte empregados, bem como seus potenciais riscos ambientais. Igualmente, as ações logísticas estratégicas foram identificadas, uma vez que visam atenuar ou sanar os problemas ambientais causados pelo descarte indevido do resíduo. Tais informações foram avaliadas à luz da literatura sobre Logística Reversa e seus Componentes Logísticos, levando também em conta a legislação ambiental voltada aos resíduos gerados no setor elétrico. Como resultado, a estrutura dos canais reversos da empresa foi descrita juntamente com seus processos e componentes logísticos.
\end{abstract}

Palavras-chave: logística reversa; componentes logísticos; setor elétrico.

\section{Introdução}

O suprimento de energia elétrica é imprescindível para o desenvolvimento sócio-econômico de um país e representa um importante insumo básico aos diversos setores da atividade econômica brasileira (COSTA, 2010). O contexto em que as economias brasileira e mundial estão inseridas merece destaque por representar a intensa competitividade entre as empresas, além de exigir 
estratégias mercadológicas eficientes (LEITE, 2009). Neste sentindo, a Logística Reversa fortalece a competitividade no setor elétrico quando permite agregar valor a um resíduo de pós-consumo, como o óleo mineral utilizado em transformadores de potência.

Tendo em vista que o aumento no consumo de energia elétrica foi estimado em 4,4\% no setor residencial, 4,7\% no setor industrial e, em relação a 2011, 5,1\% no comércio (EPE, 2011), o setor elétrico necessita de um tratamento para os seus resíduos. Assim, é imprescindível tratar os resíduos desse setor, utilizando a Logística Reversa, o que proporcionará vantagens competitivas, além de evitar danos ao meio ambiente.

Assim, considerando a produção e destinação adequada de resíduos no setor elétrico, surgem os questionamentos: Quais os canais reversos do Óleo Mineral Isolante, gerado pela atividade de transformação de potência do Setor Elétrico no Estado do Pará, e em que situação se encontram os componentes logísticos referentes a esses canais? Para responder essa questão, tem-se como objetivo identificar os canais reversos, tendo em vista os componentes logísticos, voltados aos resíduos de pós-consumo a partir do levantamento de informações referentes ao canal reverso em questão.

Desta forma, foi necessário o levantamento do material bibliográfico referente ao assunto, bem como das informações referentes ao canal reverso dos resíduos gerados no processo produtivo da empresa em estudo. Posteriormente, as informações referentes ao canal reverso foram aplicadas ao óleo mineral isolante para realizar uma análise baseada nos componentes logísticos. Assim, foi possível alcançar os resultados e, consequentemente, responder a questão da pesquisa.

Neste primeiro momento, foi possível ter uma noção geral da relevância do tema abordado, assim como dados relacionados ao mesmo, além da abordagem de aspectos relacionados ás considerações iniciais, justificativa, questão de pesquisa e objetivos. A Revisão Bibliográfica apresenta um levantamento bibliográfico referente aos principais temas do trabalho, tais como, a Logística Reversa, o Setor Elétrico, os Componentes Logísticos, a Legislação Ambiental e os Resíduos do Setor Elétrico. Buscou-se desenvolver esses conceitos com o intuito de proporcionar o embasamento necessário para o entendimento e solução do problema proposto. Em Material e Método da Pesquisa, o trabalho foi caracterizado segundo os objetivos e a forma da abordagem do problema, bem como as etapas existentes para o alcance dos objetivos, e o foco do estudo. No tópico relacionado à análise de dados e resultados, apresentou-se o Estudo de Caso em uma empresa do setor elétrico no Estado do Pará, na qual se levantaram os componentes logísticos operacionais relacionados à LR do Óleo Mineral. E, por fim, nas considerações finais, são analisados os resultados obtidos, relacionado-os com os objetivos propostos e a questão da pesquisa. 


\section{Revisão bibliográfica}

\subsection{Logística reversa}

A logística objetiva, segundo Bowersox, Closs e Cooper (2007), amparar as necessidades operacionais de compra, produção e atendimento às expectativas dos clientes, de tal forma que haja o envolvimento entre os pontos determinantes para que isso ocorra. De acordo com Ballou (2006), o valor da logística consiste no tempo e no lugar, o que agrega valor para clientes, fornecedores e demais envolvidos. Ainda segundo esse autor, os fluxos logísticos podem ser caracterizados em quatro Sistemas Logísticos: Logística Interna ou de Produção; Logística de Suprimentos; Logística de Distribuição e Logística Reversa.

A Logística Interna ou de Produção está ligada diretamente a cadeia de valor da empresa e busca aperfeiçoar os processos que envolvem o layout de recebimento, armazenagem e distribuição interna da empresa, bem como sistemas de informação, desenvolvimento de tecnologias de aquisição e atividades primárias de apoio (LAMEIRA, 2008).

Segundo Ballou (2006), a Logística de Suprimentos analisa os fluxos de entrada no sentido jusante da cadeia de suprimentos, selecionando fornecedores que supram a empresa de insumos adequados à sua necessidade, levando em conta o seu transporte, armazenagem e estocagem. Já a Logística de Distribuição analisa e considera os fluxos de saída no sentido jusante da cadeia de suprimentos, sendo responsável pelos processos operacionais e de controle, como a estocagem, a armazenagem e a distribuição, levando o produto desde o ponto de fabricação até ao ponto de consumo do produto (NOVAES, 2007).

Por fim, a Logística Reversa (LR) atua no sentido montante da cadeia de suprimentos, tendo a função de operar e controlar os fluxos de materiais e informações logísticas correspondentes ao retorno dos bens de pós-venda e de pós-consumo no ciclo produtivo (LEITE, 2009). Vale ressaltar que a importância da LR cresce à medida que o ciclo de vida dos produtos vai decrescendo devido ao rápido avanço da tecnologia. Quando se tornam obsoletos, os produtos podem voltar ao ciclo dos negócios por meio da Logística Reversa, o que agrega valor por meio do reuso, remanufatura, reciclagem ou destinação final mais adequada, neste último caso, quando a realização de nenhuma das alternativas anteriores for possível. A importância estratégica dos canais de distribuição reversos reflete o pensamento globalizado que visa atender os interesses governamentais, ambientais e sociais, no que tange a revalorização ou destinação dos resíduos produzidos na indústria. Para que esses resíduos sejam direcionados para canais de revalorização deve-se, primeiramente, classificá-los, de acordo com o seu ciclo de vida útil, como duráveis, semiduráveis e descartáveis, em seguida deve-se definir sua destinação como: reuso, remanufatura, reciclagem, disposição final e mercado secundário. 
A Logística Reversa de pós-consumo reaproveita os componentes e os materiais e incentiva novas aquisições, valorizando a questão ecológica, o que contribui para a imagem corporativa da empresa e para a competitividade por meio da redução de custos (LEITE, 2009). Segundo TibbenLembke e Rogers (2002), a LR tem a desvantagem de não trabalhar necessariamente com informações consistentes de estoque. Além disso, o destino do produto que utiliza os canais reversos não é único, pois depende da classificação prévia, o que aumenta a complexidade do sistema. Dessa forma, entende-se o porquê de ter a LR como uma atividade autônoma.

\subsection{Os canais da logística reversa}

A rede de distribuição reversa de pós-consumo constitui-se na entrada dos produtos de pósconsumo, advindos de domicílios, comércios, indústria e assistência técnica geral; da localização das etapas de consolidações quantitativas, geográficas e de processamento, que norteiam o número de armazéns avançados e centros de distribuição reversos; do processamento industrial, destinador dos produtos de pós-consumo, para transformá-los em novos produtos ou materiais secundários; e da redistribuição que pode ocorrer para o mercado original, secundário, industrial e outros.

Os pontos estratégicos e operacionais do planejamento de uma atividade de retorno de um produto envolvem decisões relativas aos objetivos da LR, aos mercados dos produtos reaproveitados, às interações de atividades nas etapas reversas etc., com o foco de adequar os fluxos de materiais e mercadorias em toda cadeia logística (LEITE, 2009).

O desempenho dos canais reversos, segundo Chopra e Meindl (2003), pode ser medido por quatro elementos principais: estoques, transportes, instalações e informação. Os estoques são a quantificação dos recursos usados em uma organização, servindo como elemento regulador e amortecedor de incertezas no transporte, na fabricação e no processamento (DAVES, AQUILANO e CHASE (2001, p. 469)). O transporte representa a locomoção do produto pelas diferentes seções da cadeia de suprimentos, gerando fluxos financeiros, de estoques e de informação. Por último, a informação consiste em dados ou análises de estoques, transportes, instalações, fornecedores e clientes que consideram os sistemas de tecnologias da informação, os recursos humanos e matérias que agregam valor à empresa (MELO e ALENCAR (2010, p.104); não possui apenas um sentido (jusante ou montante) na cadeia de suprimentos e precisa sempre ser veloz e eficiente na conexão efetiva entre os seus diversos estágios).

Ao colocar em prática a LR surge a necessidade de uma integração forte entre os sistemas e da participação de parceiros internos e externos (CHAVES, 2009). A LR não é uma tarefa simples, pois requer organização e controle para que haja um gerenciamento de qualidade. Dessa forma, Figueiredo et al (2003) evidenciaram alguns fatores críticos para um bom desempenho da Logística 
Reversa: controles de entrada; processos padronizados; tempo de resposta; sistemas de informação; rede logística e relações colaborativas entre clientes e fornecedores.

\subsection{Aspectos estratégicos da logística reversa na cadeia de suprimentos}

A LR se torna estratégica por agregar valor ao produto, muitas vezes, com um viés sócio ambiental, elementos bastante explorados pelo marketing. Isso ocorre por meio das adequações às questões ambientais, diferenciação da imagem corporativa, elevação do nível de serviço oferecido ao cliente, dentre outros fatores, como redução de custos que afetam diretamente a competitividade de uma empresa. Portanto, vantagens competitivas tangíveis e intangíveis são obtidas a partir da adoção de estratégias voltadas à LR.

As vantagens tangíveis envolvem um bom retorno dos investimentos e novos mercados, a retenção de clientes e empregados, devido à oferta de produtos ecologicamente corretos, o aumento de compras online e off-line, referente às políticas como a escolha do local de retorno, período prolongado de retorno, rápido reembolso e pagamento do transporte, além dos possíveis fornecimentos de introspecções detalhadas a respeito da eficácia dos fluxos das mercadorias e afins. Em relação às vantagens intangíveis, há melhorias na imagem corporativa, oportunidade de avaliar a satisfação, opinião e reação do cliente sobre os atributos físicos do produto retornado, benefícios quanto às informações de incerteza e de magnitude dos retornos, e mercados potenciais para várias operações da recuperação, além de facilitar que varejistas e fornecedores adquiram informações a partir dos produtos retornados.

\subsection{Gerenciamento da cadeia de suprimentos}

Segundo Chopra e Meindl (2011), o Gerenciamento da Cadeia de Suprimentos (GCS), denominado também de Supply Chain Management (SCM), é definido como a gestão de ativos e produtos, informações e fluxo de fundos, com o intuito de aumentar o excedente total da cadeia, além de ser composto de partes que envolvem-se direta e indiretamente na realização do pedido do cliente. Com essa ideia, muitas vezes esse termo é substituído por "teia de suprimentos", já que é possível passar a ideia de inúmeros participantes em cada estágio.

\subsubsection{Componentes logísticos}

Segundo Alencar e Melo (2012), os componentes de desempenho logístico ou componentes logísticos podem ser divididos em duas categorias: Operacionais e Estratégicos. De acordo com Monteiro et al (2013), todos os recursos materiais, humanos, informacionais etc., associados a 
Instalações, Estoques, Transportes ou Informações estão fortemente relacionados às atividades logísticas, devendo ser, portanto, considerados em análises para retificação, ou proposição de novas, estratégias logísticas, uma vez que influenciam, sob aspectos diferentes, o desempenho das operações logísticas associadas a estas estratégias. Por isso, tais componentes são chamados Componentes Logísticos Operacionais.

Uma vez que geram impactos na capacidade e nos custos de serviços ao cliente, as Instalações são componentes logísticos que exigem certa atenção, sobretudo em relação a decisões associadas a localização, quantidades a serem implantadas e tamanho/ capacidade de armazenagem (BALLOU, 2006). Os Estoques, por sua vez, devem ser associados à contabilização de qualquer recurso material utilizado em uma empresa (DAVES; AQUILANO e CHASE, 2001), sendo o ideal tentar reduzi-los de tal forma a somente atender à demanda prevista, uma vez que podem representar custos bastante elevados (BARBOSA JUNIOR; LEITÃO e MELO, 2009). Os transportes constituem um componente logístico que também gera impactos diretos nos custos, sendo responsáveis pela velocidade com que os produtos são movimentados até os clientes, exercendo grande influência nas principais decisões logísticas (CHOPRA E MEINDL, 2011). Por fim, as Informações consistem em dados e análises referentes aos demais componentes logísticos, o que torna esse componente logístico crucial ao desempenho logístico, uma vez potencializa maior integração entre os demais componentes e, consequentemente, redução de incertezas logísticas (CHOPRA E MEINDL, 2011). Ainda segundo Monteiro et al (2013), na prática, tais componentes estão fortemente interrelacionados, uma vez que decisões referentes, pontualmente, a cada um deles influenciam o desempenho dos demais. Assim, as decisões logísticas associadas aos componentes operacionais, devem considerar os resultados de trocas compensatórias (trade-offs) entre custos ou entre níveis de serviço.

Já Custos e Serviço ao cliente, por serem variáveis cujos valores são mais tangíveis aos clientes, influenciando suas percepções de valor, satisfação e fidelização, constituem os Componentes Logísticos Estratégicos, sendo seus resultados diretamente influenciados pela melhor relação ou arranjo entre os componentes logísticos operacionais (MELO e ALENCAR, 2010; MONTEIRO et al, 2013). A Figura 1 ilustra a relação entre os componentes logísticos, considerando seus respectivos contextos (ambientes) de aplicação.

A metodologia aplicada nesta pesquisa considera exatamente uma abordagem orientada pelos componentes logísticos operacionais, para identificar e caracterizar os recursos envolvidos nas operações de logística reversa desenvolvidas na organização em foco. 


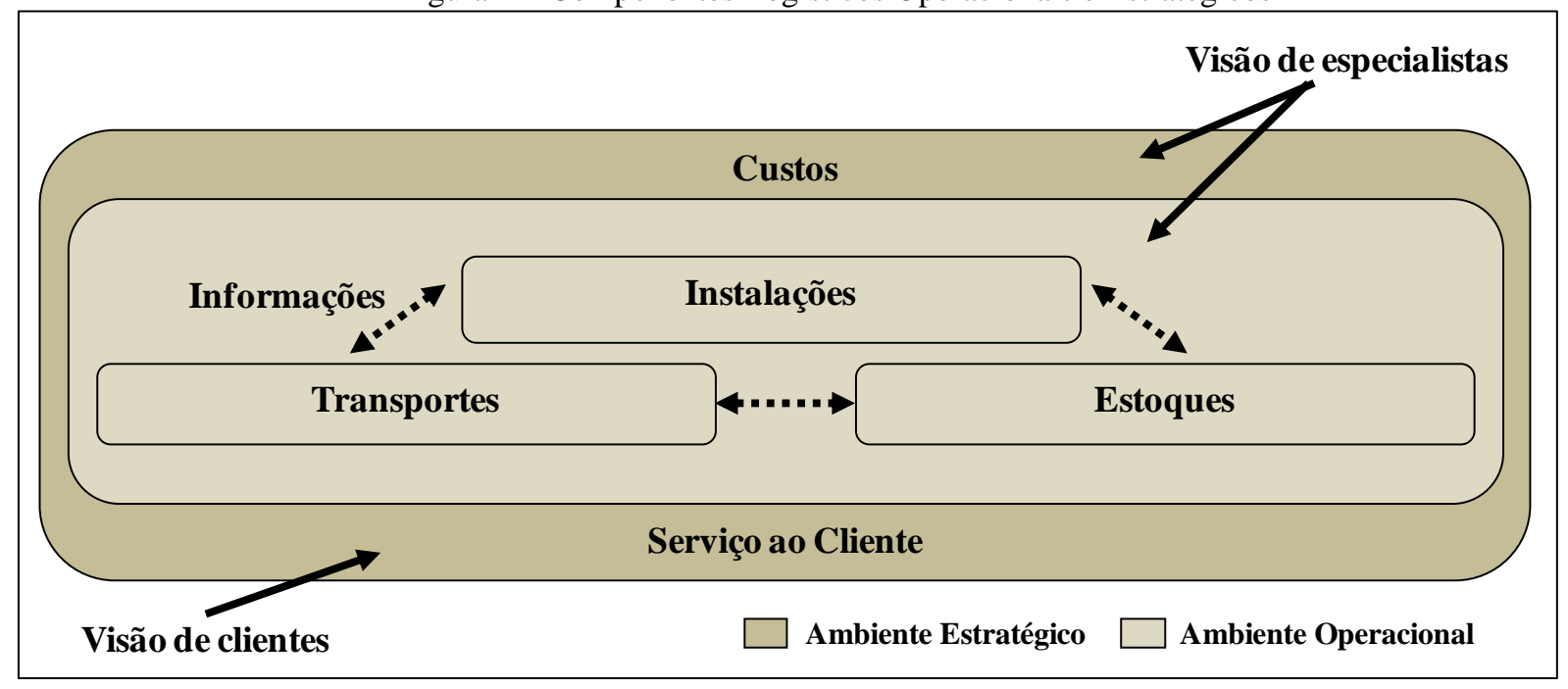

Fonte: Monteiro et al (2013)

\subsection{A produção de resíduos em uma empresa do setor elétrico}

O Setor Elétrico Brasileiro (SEB) é uma das bases para o desenvolvimento do Brasil por proporcionar um maior desenvolvimento aos vários setores da economia. Cerca de $\mathrm{R} \$ 65,9$ bilhões são voltados para o SEB, o que demonstra a sua relevância para o futuro do país. No Brasil, com o processo de desestatização das empresas do setor elétrico e a abertura do mercado de energia elétrica, houve a divisão dos sistemas elétricos em geração, transmissão, distribuição e comercialização (LEÃO, 2011).

O Governo Federal, para gerenciar esse novo modelo, criou uma nova estrutura organizacional, na qual, ainda segundo Leão (2011), cada agente do setor elétrico possui funções essenciais. Dentre esses, no Ambiente de Contratação Regulada (ACR) estão as Agências Estaduais de Energia Elétrica; Eletrobrás; Agentes Setoriais, nos quais estão inclusos a ABRAGE, ABRATE, ABRADEE, ABEER, ABRACEEL, ABRACE, APINE E ABDAN.

De acordo com Nogueira (2007), promover o uso inteligente da energia, reduzir custos e produzir ganhos de produtividade e de lucratividade, com uma visão de desenvolvimento sustentável, são metas de uma política de ação referente à eficiência energética. No entanto, é preciso reduzir o consumo de energia primária em qualquer etapa da cadeia de transformação, e isso pode ser feito através de políticas e práticas redutoras de custos de energia, como: planejamento integrado dos recursos; eficiência na geração, transmissão e distribuição; e eficiência no uso final (NUNES, 2010). Conforme a Organização para Cooperação e Desenvolvimento Econômico (1997) apud Menkes (2004), a principal missão para criar um sistema de energia sustentável é utilizar as inovações tecnológicas de maneira rápida, disseminá-las e adaptá-las ao comportamento dos consumidores. 
Vale ressaltar que existem Leis, Resoluções, Instruções Normativas, Decretos, Portarias e Normas Técnicas, que dispõe sobre resíduos do setor elétrico; e que constitui prioridade o embasamento de algumas informações gerais pertinentes na elaboração de estratégias de LR. Conforme Ribeiro e Morelli (2009, p.9), os resíduos variam de acordo com as práticas de consumo e com os métodos de produção, os quais se tornaram mais intensos devido ao aperfeiçoamento das técnicas de produção. O início da atividade agrícola e da produção de ferramentas de trabalho e de armas levou ao surgimento dos restos de produção e dos próprios objetos, após a sua utilização.

Consoante com a NBR 10.004/2004, da Associação Brasileira de Normas Técnicas (ABNT), os resíduos sólidos são definidos em resíduos no estado sólido e semissólido, que resultam de atividades da comunidade de origem industrial, doméstica, hospitalar, comercial, agrícola, de serviços e de varrição. Ficam incluídos nesta definição os lodos provenientes de sistemas de tratamento de água, gerados em equipamentos e instalações de controle de poluição, bem como determinados líquidos cujas particularidades tornem inviável seu lançamento na rede pública de esgotos ou corpos d'água, ou exijam para isso soluções técnicas.

A empresa em estudo gera e transmite energia elétrica a nove estados da Amazônia Legal e, ao longo destes processos, alguns resíduos, potencialmente prejudiciais ao meio-ambiente, são gerados e precisam ter seus destinos monitorados. Nesse caso, a empresa em estudo faz o acompanhamento de uma empresa terceirizada responsável pelo transporte desses resíduos até o seu destino final. A empresa geradora de energia elétrica faz o monitoramento da geração, coleta, acondicionamento, armazenamento temporário, transporte interno e externo, até a disposição final desses resíduos.

Os resíduos produzidos pela empresa, e de interesse para este artigo, são os Óleos Minerais Isolantes, também conhecidos como óleos de transformador que possuem elevadas características isolantes e estabilidade em altas temperaturas, além de serem elementos fluidos. A sua maior utilidade ocorre em alguns tipos de transformadores elétricos; reatores de potência; capacitores de alta tensão; chaves e comutadores; e outros equipamentos elétricos. As principais funções são as de garantir o isolamento elétrico; extinguir descargas elétricas parciais e arcos elétricos; e servir como meio de troca térmica para a refrigeração dos equipamentos.

Os resíduos do óleo isolante mineral utilizado nos transformadores elétricos foram escolhidos neste artigo por serem usados em equipamentos de alto valor agregado e de grande importância operacional; pela alta quantidade de resíduos gerada na transformação de energia; por sua considerável taxa de reciclabilidade; e o grande dano ambiental, em caso de uma destinação inadequada. Este insumo é um elemento fundamental para o funcionamento dos transformadores e trafos (que são utilizados para transmitir energia ou potência elétrica de um circuito a outro), no que se refere ao isolamento e ao resfriamento dos enrolamentos destes equipamentos. 


\section{Material e método da pesquisa}

A pesquisa realizada nesse trabalho pode ser classificada de quatro diferentes maneiras: Aplicada, Qualitativa, Exploratória e Estudo de Caso (SILVA E MENEZES, 2005, p.20-21). Nesse sentido, esta pesquisa é classificada como Pesquisa Aplicada, uma vez que tem como objetivo a geração de conhecimento para aplicação prática e voltada à resolução de problemas específicos. Sob o ponto de vista da forma de abordagem do problema, é possível caracterizar essa pesquisa como Qualitativa, pois consiste em uma análise desenvolvida a partir de observações e conversas com os colaboradores da empresa em questão. Entretanto, ainda é possível atribuir mais duas classificações para a pesquisa: Exploratória e Estudo de Caso. A primeira classificação é baseada no ponto de vista de seus objetivos, pois proporciona maior familiaridade com o tema estudado; e a segunda, devido o seu envolvimento com o estudo aprofundado e pertinente de um ou poucos objetos, de tal forma que seja possível um amplo e detalhado conhecimento do mesmo.

Este trabalho possui algumas etapas que merecem ser destacadas. A primeira etapa consiste no levantamento bibliográfico e na abordagem de temas referentes à Logística Reversa, ao Setor Elétrico, aos Componentes Logísticos, a Legislação Ambiental e aos Resíduos do Setor Elétrico. A segunda etapa limita-se ao levantamento de informações referentes ao canal reverso dos resíduos gerados nos processos produtivos da empresa estudada. Posteriormente, tendo como base as informações gerais sobre os resíduos, o estudo foi voltado ao resíduo de Óleo Mineral Isolante e, assim, este foi analisado à luz dos componentes logísticos, focando no alcance dos objetivos do estudo. Por fim, os resultados foram alcançados, de tal forma que os objetivos propostos também foram atingidos e a questão levantada da pesquisa foi respondida.

Este trabalho tem como objetivo identificar os recursos envolvidos no desenvolvimento das operações de Logística Reversa dos resíduos gerados no processo produtivo de uma empresa do Setor Elétrico no estado do Pará de maneira qualitativa, com foco na análise dos canais reversos do resíduo de Óleo Mineral Isolante, tendo como base os componentes logísticos operacionais, que por sua vez, foram identificados e analisados em cada uma das etapas - coleta, acondicionamento, armazenamento, transporte e destinação final - nos canais reversos do resíduo em questão.

\section{Análise de dados e resultados}

Nesta seção, é apresentado o Estudo de Caso realizado em uma empresa do Setor Elétrico atuante no Estado do Pará, com o intuito de realizar um levantamento dos componentes logísticos operacionais inerentes à LR dos resíduos de Óleo Mineral Isolante oriundo de algumas da atividade de transformação de energia elétrica, realizadas durante o processo de transmissão de energia desenvolvido pela empresa estudada. 


\subsection{Produção do óleo mineral na empresa estudada}

O óleo isolante é utilizado em 23 transformadores de grande porte (cuja capacidade em litros de óleo varia de 46.837 a 76.400 litros), sendo 2 transformadores de médio porte (capacidade de 8000 litros) e 21 transformadores de pequeno porte (com capacidade para 3000 litros). Estes equipamentos estão divididos em: "Principais" cuja função é elevar a tensão de saída da empresa (13,8 KV - 500KV); e "Auxiliares" que têm o papel de elevar a tensão de saída $(13,8 \mathrm{KV}$ - $69 \mathrm{KV})$ para a distribuição local e alimentação dos serviços auxiliares da empresa; e ainda os de "Serviço Auxiliar" que têm a função de rebaixar a tensão $(13,8 \mathrm{KV}-69 \mathrm{KV}-440 \mathrm{KV})$ para suprir os diversos quadros de alimentação dos sistemas que compõe a empresa. A Tabela 1 contém a capacidade de Óleo Mineral Isolante dos transformadores existentes na empresa, de acordo com os fabricantes desses equipamentos.

Conforme o fabricante, a vida útil do óleo isolante mineral é de 30 anos, aproximadamente, que pode varia com as condições de operação dos transformadores. Normalmente, há uma degradação lenta das propriedades do óleo isolante. No entanto, existe no transformador um determinado potencial que gera sinistro e, quando este equipamento é submetido a distúrbios elétricos e térmicos, o óleo apresenta níveis maiores de degradação. Como resultado, ocorre a geração de gases a uma taxa acima do normal. Dessa maneira, algumas medidas se fazem necessárias para sanar problemas que comprometem a qualidade do óleo e, consequentemente, o bom funcionamento dos transformadores.

Tabela 1 - Capacidade instalada de óleo isolante nos transformadores da empresa em estudo

\begin{tabular}{cccc}
\hline Fabricante & $\begin{array}{c}\text { Quantidade } \\
\text { (trafos) }\end{array}$ & $\begin{array}{c}\text { Capacidade de } \\
\text { óleo (L/trafos) }\end{array}$ & $\begin{array}{c}\text { Capac. de óleo } \\
\text { total (L) }\end{array}$ \\
\hline F1 & 4 & 76.400 & 305.600 \\
F2 & 6 & 74.285 & 445.710 \\
F3 & 5 & 68.966 & 344.830 \\
F4 & 5 & 67.000 & 335.000 \\
F5 & 4 & 46.837 & 187.348 \\
F6 & 2 & 8.000 & 16.000 \\
F7 & 21 & 3.000 & 63.000 \\
\hline
\end{tabular}

Fonte: Autoria própria (2012)

Cada $10^{\circ} \mathrm{C}$ de temperatura acima de $60^{\circ} \mathrm{C}$ diminui, aproximadamente, pela metade a vida útil do óleo isolante. Com as condições de operação do transformador, é necessário que a cada cinco anos ele seja submetido à isolação e tratamento. Se esses processos não ocorrem, a vida útil do transformador é reduzida em 50\%. Por esse motivo, a empresa em estudo efetua a coleta de amostras do óleo isolante e as envia para um laboratório contratado, para verificar se o mesmo ainda está em boas condições. São feitos, ainda, testes físico-químicos (rigidez dielétrica, fator de potência, tensão interfacial, cor, teor de água, número de neutralização, densidade, sedimento, 
aspecto e análise cromatográfica) e os resultados desta análise são comparados aos valores préestabelecidos em normas. Caso os valores estejam fora dos especificados, o óleo isolante é trocado, o que gera o resíduo.

\subsection{Etapas do processo de logística reversa dos resíduos gerados pela empresa}

O levantamento em campo evidenciou as seguintes etapas no fluxo reverso dos resíduos:

- Identificação feita a partir da avaliação da planta de instalação, a qual permite que os resíduos gerados nos processos operacionais e administrativos sejam discernidos e registrados;

- Classificação de acordo com a Norma Brasileira (NBR) 10004/2004 e a Resolução do CONAMA n ${ }^{\circ} 313$, de 2002, que classificam os produtos em perigosos e Não Perigosos que se dividem em Classe II A (não inertes) e Classe II B (inertes);

- Coleta feita por meio de coletores identificados com cores diferenciadas, de acordo com a Resolução CONAMA nº 275, de 2001;

- Acondicionamento de acordo com o tipo de resíduo, usando tambores, bombonas, contêiner, big-bags, caixas de madeira ou papelão;

- Etiquetagem dos Recipientes, sendo que resíduos perigosos devem ser devidamente identificados com etiqueta, contendo informações como o nome do resíduo, origem, responsável, telefone, quantidade, estado físico, características, nome do responsável pela área geradora, telefone do responsável, código de classificação do resíduo de acordo com ABNT NBR 10004 ou Resolução Conama n³13, de 2002, endereço da Central de Armazenamento Provisório de Resíduos (CAPR);

- Transporte Interno realizado por veículos adequados (plataforma móvel, empilhadeiras, caminhonetes, caminhões tipo caçamba, guincho e basculante), para deslocamento do local da geração até a CAPR, acompanhados do "Manifesto Interno de Resíduos" (MIR), devidamente preenchido pela equipe de transporte;

- Armazenamento na CAPR apenas para resíduos perigosos e recicláveis;

- Medidas de Emergência da CAPR para o caso de vazamento de produtos químicos é necessário proceder de acordo com o "Procedimento para Atendimento a Pequenos Derrames e Vazamentos de Produtos Químicos";

- Monitoramento da CAPR por inspeções periódicas realizadas com o intuito de identificar possíveis vazamentos contidos, por exemplo, nos resíduos de baterias;

- Transporte externo para resíduos Classe I feito por empresa autorizada; 
- Disposição final realizada por um fornecedor contratado especializado e autorizado para transporte, tratamento e disposição final dos resíduos Classe I. A destinação de resíduos de Classe II é feita em células de inertes para alienação ou aterro municipal.

\subsection{Componentes logísticos operacionais na LR do óleo mineral}

Nessa seção, são considerados os componentes logísticos operacionais: Estoques, Transportes, Instalações e informação. Baseando-se na cadeia reversa da empresa estudada, com foco no canal reverso dos resíduos do Óleo Mineral Isolante, foram identificadas informações pertinentes relacionadas a cada um dos componentes logísticos considerados.

Os Estoques de Resíduos são planejados de acordo com a caracterização e classificação de cada um, conforme a NBR 10004/2004 e Resolução CONAMA n 313 de 2002. Os resíduos líquidos são estocados provisoriamente no Galpão de sobressalentes do Setor de Suprimentos ou Galpão de armazenamento. É possível retirar o Óleo Mineral Isolante das caixas separadoras e poços de drenagem ou diretamente do interior da máquina, em processo de manutenção. No caso de caixas separadoras e poços, os resíduos são colocados em tambores de 200 litros, vedados e identificados como Resíduo Classe I. Na segunda opção, estes resíduos são acondicionados em tanques de 25.000 litros para, posteriormente, serem destinados ao rerrefino. Ainda é necessário identificá-los como borra de óleo (óleo contaminado com água ou produtos químicos) ou óleo usado para rerrefino (óleo não contaminado com água ou produtos químicos), sendo o primeiro incinerado e o segundo revalorizado economicamente (remanufatura). Esses resíduos são acomodados no local da sua geração e, quando atingem determinado volume, são levados ao galpão de armazenamento de óleo, onde são acomodados em tambores e estocados no Setor de Suprimentos de forma documentada. Os que não se encontrarem assim, não poderão ser aceitos;

O transporte do resíduo é considerado desde a coleta até à disposição final. O Centro de Trabalho da Manutenção Mecânica retira o óleo isolante usado de todas as caixas separadoras de óleo e água, e poços de drenagens. As caixas coletoras retêm o óleo vazado e compartilham espaço com a água da chuva. A separação de água e óleo ocorre pela diferença de densidade. Internamente, o "óleo usado" é transportado do local da geração até o galpão de armazenagem por veículos adequados, podendo ser plataforma móvel, empilhadeiras, caminhonetes, caminhões tipo caçamba ou guincho e carroceria aberta ou basculante. No transporte externo, a primeira parte consiste em transferir os insumos do tanque de contenção do óleo vazado dos transformadores para o caminhão tanque por bombeamento. A segunda parte é realizada pelos caminhões de carroceria;

As instalações físicas têm a finalidade de armazenar, anualmente, cerca de 150.000 litros de resíduo de óleo, para acomodá-los desde a geração até a destinação final nos centros de armazenagem. As áreas de instalações referentes ao óleo usado são: as caixas separadoras de óleo e 
água, os poços de drenagens e o galpão de armazenagem de oleo. As caixas separadoras de óleo e água e os poços de drenagens são utilizados na etapa de Coleta do Óleo Usado, retendo o óleo vazado das máquinas, evitando o transbordamento de óleo à jusante do rio e a provável contaminação da água. O galpão de armazenagem recebe o óleo e armazena-o em tambores sobre pallets. Esse galpão tem uma área coberta, ventilada e com barreiras de contenção de 20 x 50m, conforme as normas da NBR 12235/92. O espaço que abriga o óleo novo (ainda não usado) comporta 2.916 tambores. A empresa possui requisitos para que haja um Gerenciamento da Gestão do Resíduo eficiente, logo o galpão é operado para minimizar e controlar a ocorrência de fogo, explosão ou liberação de algum componente químico que afete a água e o solo, além de existir uma identificação e sinalização quanto aos acessos internos e externos.

Toda a informação considerada no processo é organizada em fluxos gerados no Sistema de Gestão Ambiental (SGA), o qual estabelece requisitos para que toda e qualquer atividade respeite a política ambiental da empresa. Utiliza-se a intranet corporativa como fonte de informação para a gestão do óleo isolante, e tecnologias de informação para que haja um suporte em relação aos sistemas de informações utilizados tanto em serviços/operações emergenciais como para os convencionais, quais sejam: Sistema SAP R/3 e Sistema Prosignet. Isso indica o quanto as informações são organizadas e documentadas para que o fluxo reverso do óleo isolante seja eficiente. A maioria da documentação preenchida ou recebida pelo Setor de Suprimentos, com informações sobre o óleo usado, é arquivada na Coordenação do Sistema de Gestão Ambiental (CSGA), responsável pelo Gerenciamento dos Resíduos. Essa documentação engloba os seguintes formulários: armazenamento e movimentação de resíduos, movimentação de resíduo mensal, formulário de descarte do resíduo, planilha de origem, classificação e destinação final dos resíduos, check list de transporte de produto/resíduo perigoso.

A Comunicação Interna (CI) é o documento utilizado para comunicar internamente sobre diversos assuntos, porém, há outras ferramentas para que isso ocorra como quadro de avisos, eventos internos, banners, faixas, cartazes, reuniões da CSGA, relatórios ambientais, correio eletrônico, comunicado verde e jornal novo tempo. A comunicação externa envolve os clientes, a comunidade e os órgãos públicos, e ocorre por meio de sugestões, reclamações, perguntas, contatos com os órgãos ambientais e outros, podendo ser realizada através de eventos externos, revista corrente contínua, banners, faixas, cartazes, visitas guiadas à empresa e boletins.

\section{Considerações finais}

O presente artigo atingiu seu objetivo de identificar e analisar os componentes logísticos dos canais reversos do óleo mineral isolante em uma empresa do setor elétrico no Estado do Pará. Observou-se que a empresa objeto deste estudo apresenta uma estrutura bem definida de seus 
processos de logística reversa de resíduos. Processos esses que vão desde a classificação passando pela estocagem e finalizando com a destinação final desses resíduos conforme legislação pertinente em vigor. Para que os canis reversos utilizados pela empresa funcionem adequadamente os componentes logísticos: transporte, estocagem, instalações e informação, são gerenciados de forma coordena de maneira a permitir sincronia na movimentação do resíduo através dos canais reversos observados.

Para estudos futuros, sugere-se a identificação de outros resíduos de igual ou maior potencial de impacto ambiental, entre aqueles gerados pela empresa, em relação tanto aos componentes logísticos operacionais quanto aos estratégicos (custos e serviço ao cliente). As análises de custos e serviço ao cliente permitiriam a definição dos processos logísticos reversos mais adequados, em que a empresa objeto de estudo potencializaria mais responsividade ou mais eficiência na tentativa de alinhamento às suas estratégias organizacionais. A estimativa do custo do ciclo de vida do ativo colaboraria, ainda, na elaboração de uma previsão mais consistente e na análise dos custos de produção, facilitando a melhor alocação dos investimentos e a, consequente, redução de custos.

\section{Abstract}

This article aims to identify the reverse channels of post-consumer waste, from the perspective of its logistics components in an electrical company in the state of Pará. Therefore, a literature on reverse logistics and logistical components was performed, which allowed, together with the field survey, describe the reverse strand of the insulating oil residue produced by study object. Thus, this waste were identified on their volumes processed, the processes involved in the transport and handling, and the main points of discharge employees as well as their potential environmental risks. Also, the strategic logistical actions were identified, since they aim to mitigate or remedy the environmental problems caused by improper disposal of waste. Such information has been reviewed in the light of the literature on Reverse Logistics Logistics and its components, also taking into account the targeted waste generated in the electricity sector environmental legislation. As a result, the structure of the reverse channel is now described together with its logistic processes and components.

Keywords: Reverse logistics; Logistics components; Mineral insulating oil; Electrical Industry.

\section{Referências}

ALENCAR, E. D. M.; MELO, A. C.S. Estudo exploratório sobre a logística na cadeia produtiva do dendê no Estado do Pará: Uma abordagem sob a ótica de componentes de desempenho operacionais. XIX SIMPEP Simpósio de Engenharia de Produção. Bauru. 2012.

BALlOU, Ronald. H.. Gerenciamento da Cadeia de Suprimentos/Logística Empresarial. 5 ed. Porto Alegre: Bookman, 2006.

BARbOSA JUNiOR, I. O.; LEITAO, D. R.C.; MELO, A. C.S. Análise da Cadeia Produtiva do Setor de Carnes Bovinas do Estado do Pará: um estudo focado no desempenho logístico a luz da etapa de abate. XXIX ENEGEP Encontro Nacional de Engenharia de Produção. Salvador. 2009. 
BOWERSOX, Donald J. ; CLOSS, David J.; COOPER, M. Bixby. Gestão da cadeia de suprimentos e logística. Rio de Janeiro: Elsevier, 2007. (EPE, 2011).

CHAVES, Gisele de Lorena Diniz. Logística Reversa de pós-venda para alimentos derivados de carne e leite: Análise dos retornos de distribuição. Trabalho de Conclusão de Curso (Programa de Pós-Graduação em Engenharia de Produção) - Universidade Federal São Carlos, $2009 . \quad$ Disponível em: <http://www.bdtd.ufscar.br/htdocs/tedeSimplificado/tde_arquivos/1/TDE-2009-07-28T125048Z2269/Publico/2403>.

Acesso em: 24 Jun. 2013.

CHOPRA, Sunil; MEINDL, Peter. Gerenciamento da Cadeia de Suprimentos: estratégia, planejamento e operação. São Paulo: Prentice Hall, 2003.

CHOPRA, Sunil; MEINDL Peter. Gestão da cadeia de suprimentos - Estratégia, planejamento e operações. $4^{\mathrm{a}}$ edição. São Paulo: Pearson. 2011

COSTA, Tammy Monteiro. Análise da logística de suprimentos de uma empresa de energia no estado do Pará: Uma metodologia orientada à avaliação dos componentes de desempenho logístico. Trabalho de Conclusão de Curso (Graduação em Engenharia de Produção) - Universidade Do Estado do Pará, Belém, 2010.

DAVES, Mark M.; AQUILANO, Nicholas J; CHASE, Richard B. Fundamentos da Administração da Produção. 3. ed. Porto Alegre: Bookman, 2001.

FIGUEIREDO, Kleber Fossati, et al. Logística e Gerenciamento da Cadeia de Suprimentos: Planejamento do fluxo de produtos e dos recursos. São Paulo: Atlas, 2003.

LEÃO, R.. GTD - Geração, Transmissão e Distribuição de Energia Elétrica. UFC, 2011. Disponível em:<http://ygo.pesqueira.ifpe.edu.br/didaticos/rd_I_introducao.pdf>. Acesso em: 15 mai.2012.

LEITE, Paulo Roberto. Logística Reversa: meio ambiente e competitividade. 2. ed. São Paulo: Pearson Prentice Hall, 2009.

MELO, André Cristiano Silva; ALENCAR, Evander Dayan de Matos. Análise de cadeias produtivas: uma abordagem orientada pela análise de componentes de desempenho logístico. In: OLIVEIRA, R. M. S. de (Org.). Engenharia de Produção: tópicos e aplicações. Belém: EDUEPA, 2010. cap 4, p. 99-124. Volume 1.

MENKeS, M. Eficiência Energética, Políticas Públicas e Sustentabilidade. 2004. 293 p. Tese (Doutorado em Desenvolvimento Sustentável) - Universidade de Brasília, Brasília, 2004. Disponível em: <http://www.unbcds.pro.br/publicacoes/MonicaMenkes.pdf>. Acesso em: 16 mai. 2012.

MONTEIRO, Nathália Jucá; MELO, André Cristiano Silva; BRANCO, Najmat Celene Nasser Medeiros; COELHO, Guilherme Freitas; DA SILVA, Elizabeth Cristina Silva. Mapeamento dos Processos Logísticos de Operações de Lavra da Cadeia Produtiva do Minério de Ferro Produzido no Estado do Pará. XX SIMPEP - Simpósio de Engenharia de Produção. Bauru, São Paulo. 2013.

NOGUEIRA, F. H. F. de M. GOVERNO DO ESTADO DO RIO DE JANEIRO. SECRETARIA DE ESTADO DE PLANEJAMENTO E GESTÃO. Política de ação: eficiência energética. Rio de Janeiro, 2007. Disponível em: <http://www.educacao.rj.gov.br/arq_pdf/Cartilha_SEPLAG_Eficiencia_Energetica.pdf>. Acesso em: 26 mai. 2012.

NUNES, A.L.R. Eficiência Energética em Prédios Públicos. 2010. 135 p. Trabalho de Conclusão de Curso (Graduação em Engenharia Elétrica) - Universidade Federal do Rio Grande do Sul, Porto Alegre, 2010. Disponível em: <http://www.lume.ufrgs.br/bitstream/handle/10183/33024/000788188.pdf?sequence=1>. Acesso em: 20 mai. 2012.

RIBEIRO, Daniel Véras; MORELLI, Márcio Raymundo. Resíduos Sólidos: problema ou oportunidade? . Rio de Janeiro: Interciência, 2009, 158 p.

ROCHA, Carlos Ivan Lima da; RODRIGUES, Maruschka Carneiro. Análise da Logística Reversa de Pós-consumo de Resíduos do Setor Elétrico: Um Estudo Aplicado ao óleo isolante de Transformadores em uma empresa no estado do Pará./ Carlos Ivan Lima da Rocha, Maruschka Carneiro Rodrigues; - Belém: UEPA - Universidade do Estado do Pará / CCNT - Centro de Ciências Naturais e Tecnologia 2012.

SILVA, Edna Lúcia da; MENEZES, Estela Muszkat. Metodologia da Pesquisa e Elaboração de Dissertação. 4. ed. Florianópolis: UFSC, 2005, 139 p. 


\section{DADOS DOS AUTORES:}

\section{Maruschka Carneiro Rodrigues}

Universidade do Estado do Pará, UEPA

Engenheira de Produção,

Endereço: Travessa Enéas Pinheiro, 2626. Belém - Pa. Brasil.

Telefones para contato: (55) 91 3276-4011/3131-1907

e-mail: maruschka.cr@gmail.com

\section{Nathália Almeida Castro Rodrigues}

Universidade do Estado do Pará, UEPA

Formanda do curso de Engenharia de Produção,

Endereço: Travessa Enéas Pinheiro, 2626. Belém - Pa. Brasil.

Telefones para contato: (55) 91 3276-4011/3131-1907

e-mail: nathaliarods@hotmail.com

\section{André Cristiano Silva Melo}

Universidade do Estado do Pará, UEPA

Professor D.Sc. em Engenharia de Produção, e Coordenador dos laboratórios CONCEPT e NILO

Endereço: Travessa Enéas Pinheiro, 2626. Belém - Pa. Brasil.

Telefones para contato: (55) 91 3276-4011/3131-1907

e-mail: acsmelo@yahoo.com.br

\section{Denilson Ricardo de Lucena Nunes}

Universidade do Estado do Pará, UEPA

Professor D.Sc. em Engenharia de Produção.

Endereço: Travessa Enéas Pinheiro, 2626. Belém - Pa. Brasil.

Telefones para contato: (55) 91 3276-4011/3131-1907

e-mail: denilson.lucena@ibest.com.br

Submissão: 2014-10-06

Aceito em: 2015-05-08 